\title{
Computed tomography investigation of the material structure in clinch joints in aluminium fibre-reinforced thermoplastic sheets
}

\author{
Benjamin Gröger ${ }^{1}$ (D) Daniel Köhler ${ }^{1} \cdot$ Julian Vorderbrüggen $^{2} \cdot$ Juliane Troschitz $^{1} \cdot$ Robert Kupfer $^{1}$. \\ Gerson Meschut ${ }^{2} \cdot$ Maik Gude $^{1}$
}

Received: 18 October 2021 / Accepted: 22 November 2021 / Published online: 7 December 2021

(c) The Author(s) 2021

\begin{abstract}
Recent developments in automotive and aircraft industry towards a multi-material design pose challenges for modern joining technologies due to different mechanical properties and material compositions of various materials such as composites and metals. Therefore, mechanical joining technologies like clinching are in the focus of current research activities. For multi-material joints of metals and thermoplastic composites thermally assisted clinching processes with advanced tool concepts are well developed. The material-specific properties of fibre-reinforced thermoplastics have a significant influence on the joining process and the resulting material structure in the joining zone. For this reason, it is important to investigate these influences in detail and to understand the phenomena occurring during the joining process. Additionally, this provides the basis for a validation of a numerical simulation of such joining processes. In this paper, the material structure in a joint resulting from a thermally assisted clinching process is investigated. The joining partners are an aluminium sheet and a thermoplastic composite (organo sheet). Using computed tomography enables a three-dimensional investigation that allows a detailed analysis of the phenomena in different joining stages and in the material structure of the finished joint. Consequently, this study provides a more detailed understanding of the material behavior of thermoplastic composites during thermally assisted clinching.
\end{abstract}

Keywords Multi-material-design $\cdot$ Clinching $\cdot$ Composite $\cdot$ Computed tomography (CT)

\section{Introduction}

The environmental awareness of customers and the upcoming demands in terms of energy efficiency lead to new innovative products for the mobility sector. Alternative materials like composites are used to reduce the mass of vehicles or systems in motion. Using different materials with different

All authors contributed equally to this work.

Benjamin Gröger

benjamin.groeger@tu-dresden.de

Daniel Köhler

daniel.koehler3@tu-dresden.de

Julian Vorderbrüggen

julian.vorderbrueggen@1wf.upb.de

Juliane Troschitz

juliane.troschitz@tu-dresden.de

Robert Kupfer

robert.kupfer@tu-dresden.de mechanical properties enables the development of advanced products in terms of stiffness, strength and lightweight degree. Such new design options using different materials require advanced joining technologies. Therefore, mechanical joining technologies for metal and non-metal materials, e.g. thermoplastic composites (TPC) are in focus of recent research [1].

Established mechanical joining technologies for metal joints [2] are often not suitable for metal-TPC-joints because

Gerson Meschut

gerson.meschut@1wf.upb.de

Maik Gude

maik.gude@tu-dresden.de

1 Institute of Lightweight Engineering and Polymer Technology, Technische Universität Dresden, Holbeinstraße 3, 01307 Dresden, Saxony, Germany

2 Laboratory for Material and Joining Technology (LWF), Paderborn University, Pohlweg 47-49, 33098 Paderborn, North Rhine Westphalia, Germany 
they do not consider the specific material properties of TPC. Therefore, adjusted joining processes had to be developed. An overview of the wide range of mechanical multi-material joints using riveting, clinching and other mechanical joining technologies is given in [3]. In [4] the application and importance of clinched joints for the further development in automotive sector is shown. Hence, new developments of different clinching processes are presented. A comparison of clinching technologies especially for TPC is given in [5]. The joining processes are characterised by the required preparation steps, the amount of process steps, tool setup and process temperature. The clinched joints manufactured by different technologies are compared in terms of material structure in the joining zone, load bearing behaviour and capacity.

In the hole-clinching process presented in [6] for TPC with a tool concept consisting of a rigid die, delaminations around the pilot hole caused by dragging the laminate were observed. However, by using a spring-loaded die, the damage could be reduced [7]. Caused by the increased hydro static pressure in the neck area of the upper metal sheet less damage occurs. Furthermore, the laminate is also supported by the spring-loaded die consisting of a center and ring pad. Thus leads to less drag of the laminate around the pilot hole while offsetting. Therefore, delamination and fibre fractures were not observed.

In a friction-assisted clinching process of aluminium and a carbon fibre reinforced thermoset (CFRP) the formability of the metal joining partner could be increased. A rotation tool induced heat by friction in the punch-sided aluminium sheet [8]. This enables a crack-reduced joining process. The joint is characterized by bending fractures and carbon fibre imprints in the neck area. Additionally, delamination between the perpendicular layers occured in the joining zone.

A joint generated with a radially opening die for aluminium and glass fibre reinforced plastic with a thermoset matrix [9] as well as CFRP is presented in [10]. The micrographes and multistage tests at different load levels show that the bending stress increases with the penetration of the metal, which leads to initial delamination and fibre fracture [9]. In the further joining process with sliding die sectors along the bulge of the aluminium, a hole in the composite is created. This generates fibre bending which avoids further delamination. The multistage tests in [9] shows delamination in the composite around the aluminium bulge at a low loading level while bending. With increasing load level in the upsetting phase, fractures occur at the edge of the die. When all fibres are failed by fracture, a hole for the bulge is formed. The formation of an undercut goes a long with a radial flow of the aluminium. The material flow compresses the fibres in radial direction. The resultant pressure compresses the delaminated area and causes closing of cracks.
Another approach of clinching is proposed by [11]. Here, a reshaping step by compression after clinching enlarged the forming of an undercut. Simultaneously, the compressive reshaping promotes a further increase in fibre buckling and delamination. A reduction of damage can be achieved by increasing the ductility of the thermoplastic matrix via heat. The effects of process-integrated heating can be seen in [12]. The main phenomenon in the outer button especially in the bottom area is debonding of metal and composite. The corner area shows effects of delamination and cracks.

Plastification is used to improve formability of TPC in many joining processes, such as in [13]. A rotating tapered pin induced heat by friction. This increases the formability of both the punch-sided metal sheet and the die-sided TPC sheet. The punch-sided sheet forms a sleeve which realigns the fibres during forming. In a second step, an undercut is formed with a forming head on the die-side. While forming, fibre fracture at the maximum deflection of the fibres around the hole and inter fibre fractures in front of the hole (in fibre direction) can occur. In order to avoid fibre damage and the reduction of the load bearing capacity, the dimensions of the tool and the elongation of the fibres have to be considered. Another interesting approach of forming by plastification is the Thermoclinching process [14]. The punch-sided TPC sheet is placed above the die-sided metal sheet with a pilot hole. The fibres above the pilot hole of the TPC are initially cut and heated up. Afterwards, the fibres are reorientated by a downward moving pin. The fibre ends moved through the pilot hole. In last state of the process, these fibres are pressed by a moveable die and forming an undercut. This joining technology enables joining of thick composite sheets without further fibre failure. The resultant material structure were investigated by computed tomography (CT).

The evaluation of the resultant material structure for three clinching processes are investigated by $\mathrm{CT}$ and micro graphs in [5]. Here, a change of the fibre path, fibre reorientations and fibre failure caused by bending and tension is observed. The fibre failure occurs after the elastic potential of the fibres is exceeded. Phenomena like delamination or voids could not be identified.

Commonly, the inner structure of a clinch joint is analysed in destructive micrographs (cf. $[8,15,16])$. However, this method only allows the investigation in a single crosssection of a specimen. In contrast, the three-dimensional material structure of a joint can be investigated by CT [14, $17,18]$. Thus, the dimension of defects and the path of fibres can be investigated.

More detailed investigations of phenomena like matrix migration processes, fibre compaction or reduction of fibre ondulations are not focused in the presented works. They are required, however, for a detailed understanding of the process and for validation of numerical simulations. Therefore, in the present paper the well-presented clinching process 
[15] is used to join aluminium sheets and multi-layer TPC sheets. Afterwards, the three-dimensional material structure is analysed using CT.

\section{Process}

The proposed joining process is a single-stage, thermally assisted clinching process for metal-TPC joints and is called Hotclinching. The process is based on a conventional clinching process with a rigid die, whereby in this particular case a split die consisting of a rigid heated sleeve and a springloaded anvil are used [15]. Cartridge heaters provide thermal support to soften the thermoplastic matrix. The advantages of this joining technology are, that no preliminary preparation step is needed and therefore the requirements regarding position accuracy are comparable low.

Figure 1 shows a schematic illustration of the Hotclinching process. After the positioning of the the joining partners between the heated split die and the blank holder (Fig. 1a), the TPC sheet is heated up via contact heating by the heated rigid sleeve. Afterwards, the blank holder moves downwards and fixes the joining partners. In the second stage the punch moves downwards (Fig. 1b). As a result, the sheets are deformed and an offsetting takes place. The offsetting phase is characterised by an application of a counter-pressure to the joint in cause of the downward stroke of the spring-loaded anvil. This improves the formability of the metal sheet (cf. [19]). Due to the applied pressure the punch-sided material flows in radial direction, which leads to the formation of an undercut (Fig. 1c). After the backward stroke of the tools, the finished joint can be released (Fig. 1d).

\section{Materials and methods}

\subsection{Material}

The materials used for the process studies and analyses of the joining zones are summarized in Table 1. Glass fibre reinforced polyamid 6 (GF-PA6) is a typical material for TPC applications with moderate thermal and mechanical
Table 1 Specification of the used materials

\begin{tabular}{lll}
\hline TPC & Material & GF-PA6 \\
& Configuration & $\mathrm{UD}\left[\left(0^{\circ} / 90^{\circ}\right)_{4}\right]_{s}$ \\
& Fibre volume content & $47 \%$ \\
& Thickness & $2 \mathrm{~mm}$ \\
Metal & Material & EN AW-6016 T4 \\
& Thickness & $1.5 \mathrm{~mm}$ \\
\hline
\end{tabular}

requirements. In previous investigations [15], an twill fabric was applied as reinforcement. In this paper unidirectional (UD) reinforced single layers are stacked to an multi-layered composite. This material was selected because of the absence of ondulation and crossing points. Therefore, it is expected that the phenomena during deformation can be observed more clearly. The UD material contains a stitch yarn in $45^{\circ}$. The ratio of the stitch yarn has an amount of $3 \%$ related to the yarn mass.

In Fig. 2 the initial structure of the used TPC with 8 UD layers in two different directions is shown. Between the yarns grey areas are identified to be PA6 as matrix rich zones. By magnification of the structure (left) also the stich yarn is visible between the orthogonal yarns. For a better understanding a slice (Fig. 2, right) of the initial material structure with the stitch yarn in a $45^{\circ}$-angle to the major yarns is shown.

\subsection{Methods}

\subsubsection{Joining equipment and characteristic dimensions}

For the manufacturing of hotclinched joints, a clinching machine TOX $^{\circledR}$ MC-4.8 from TOX ${ }^{\circledR}$ PRESSOTECHNIK $\mathrm{GmbH} \& \mathrm{Co} . \mathrm{KG}$ is used. The machine is an $\mathrm{O}$-frame press with a stroke-controlled, pneumo-hydraulic driven joining cylinder. The limitation of the stroke is implemented by the height adjustment of the die. To realise thermally assisted clinching by contact heating via cartridge heaters, the diesided tool holder is modified, as described in [5]. The temperature of the die is set to $180^{\circ} \mathrm{C}$. The heating of the TPC takes approximately $20 \mathrm{~s}$. A reduction of the temperature
Fig. 1 Schematic illustration of the Hotclinching process: (a) positioning, heating and fixation, (b) offsetting, (c) upsetting and flow pressing, (d) releasing finished joint [5]

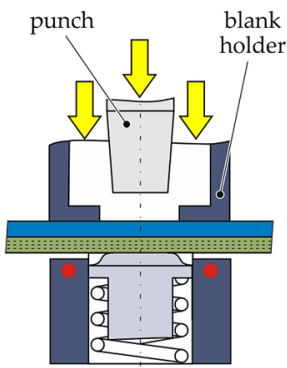

(a)

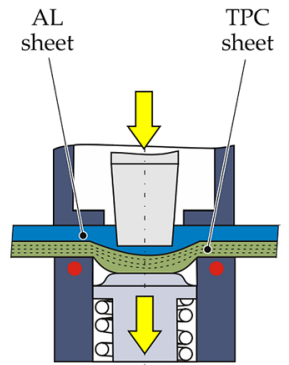

(b)

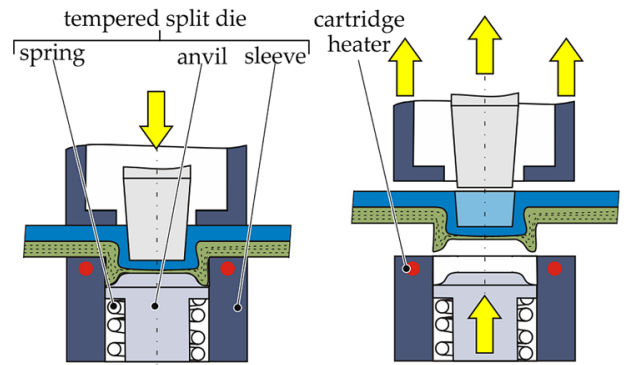

(c)

(d) 
Fig. 2 CT scan of the initial material structure

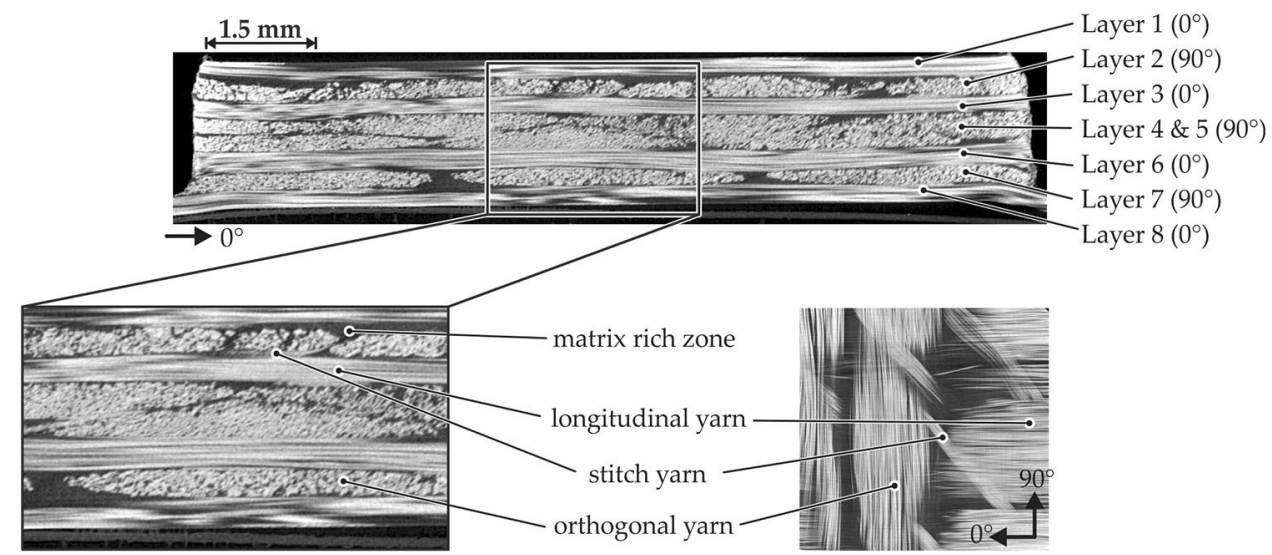

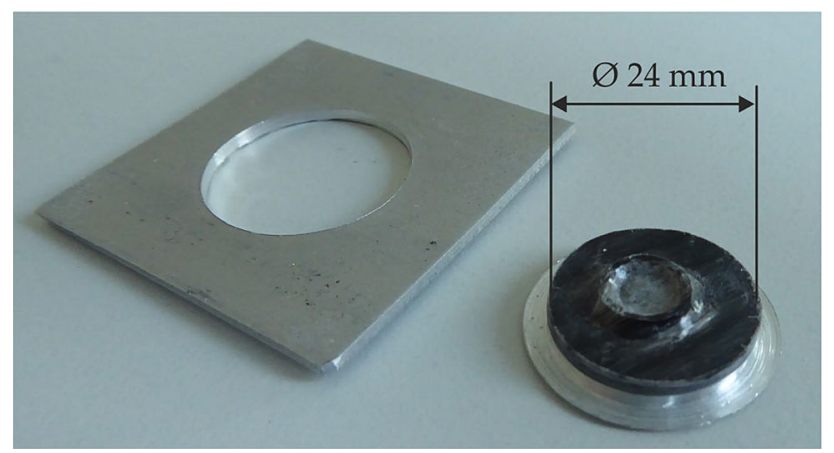

Fig. 3 Preparation of the specimens for the $\mathrm{CT}$ analysis

leads to fibre failure and reduced shear strength (cf. [15]). Heating the TPC up to melting temperature can lead to a insufficient formation of an undercut caused by the reduced stiffness of the material in the bottom area.

The punch diameter is chosen in accordance to $[5,15]$ with $5.8 \mathrm{~mm}$. The punch velocity is $2 \mathrm{~mm} / \mathrm{s}$. The initial position of the anvil is set to $1 \mathrm{~mm}$ above the rigid sleeve. The spring positioned under the anvil is not pre-loaded in the initial position and has a stiffness of $700 \mathrm{~N} / \mathrm{mm}$. This generates a counter-pressure during the joining. The end position is defined with a mechanical stop at $1 \mathrm{~mm}$ underneath the top surface of the rigid sleeve.

\subsubsection{Specimen preparation}

The clinching process was carried out with specimens of $45 \mathrm{~mm} \times 45 \mathrm{~mm}$. These specimens were cut by a water jet cutter. For the CT-analyses, smaller specimens, with a diameter of $24 \mathrm{~mm}$, are cut out after the joining process (cf. Fig. 3). The cutting is performed in manual drilling machine. The diameter is chosen in relation to the observed joining zone of around $14 \mathrm{~mm}$. The diameter of the specimen allows the assumption that no thermal stress is induced by the cutting process. For the specimen of the initial material structure an edge area of a $45 \mathrm{~mm} \times 45 \mathrm{~mm}$ plate is used.

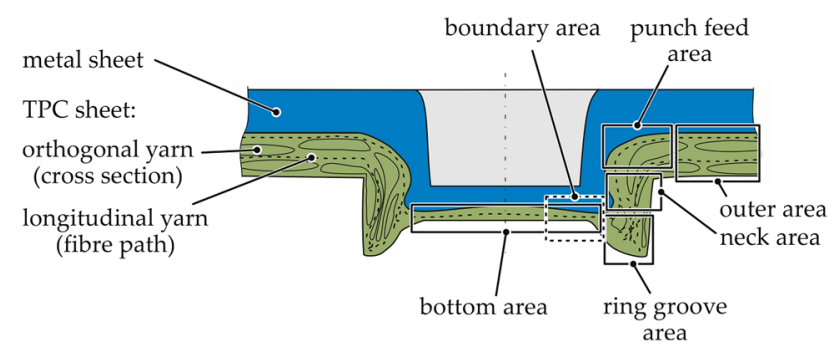

Fig. 4 Typical characteristics of the joining zone

\subsubsection{Analysis methods}

In order to ease the evaluation of the investigations, a definition of characteristic areas in the joining zone is proposed in Fig. 4.

In the present paper, specimens are investigated with a CT-system VITOMEIX L450CT (300 kV micro-focus X-ray tube) to analyse the three-dimensional material structure in the joining zone. For the investigations, an X-ray voltage of $100 \mathrm{kV}$ and a cathode current of $220 \mu \mathrm{A}$ with an exposure time of $500 \mathrm{~ms}$ are used. The CT volume is reconstructed by 1440 frames without any filters are applied. A magnification of a voxel size of $8 \mathrm{~mm}$ is realized. The specimens were scanned in a $45^{\circ}$-angle to the central beam in order to avoid $\mathrm{X}$-rays being reflected at nearly parallel surfaces (e.g. at the sheets' surfaces in the outer area), which would reduce the contrast at the respective surface.

\section{Experimental results}

In Fig. 5 the joining force-displacement curve for the investigated specimens is presented. The graph shows the typical profile for a clinching process. Furthermore, the shown red dots indicate the different phases (offsetting, upsetting and flow pressing). 
The analysis of the CT scans is focused on the change of fibre path, fibre failure and matrix migration in the different areas defined in Fig. 4. Especially, the phenomena occurring in the bottom and ring groove area during the upsetting and flow pressing phases are of interest. Therefore, CT-scans of specimens of different load level sets and finished joints were carried out. In the evaluation, the fibre direction of top layer (Layer 1) is defined as the $0^{\circ}$-direction (cf. Fig. 2).

\subsection{Global phenomena}

The material flow during joining is described by the three different load level set tests of $14.3 \mathrm{kN}$ (offsetting), 19.7 $\mathrm{kN}$ (upsetting) and $35.5 \mathrm{kN}$ (flow pressing) and the finished joint (cf. Fig. 2). The cross-sections along the $0^{\circ}$ and $90^{\circ}$ fibre direction of the reconstructed volume are given in Fig. 6. Additionally, for a quantitative analysis the bottom thicknesses of the sheets are measured (Table 2). Due to the irregular shape of the TPC sheet the thickness is measured at several points at the boundary area of the bottom. The ratio $R$ is defined as the quotient of the $\varnothing t$ in the current state and the initial sheet thickness.

In general, all specimens exhibit fibre fractures, but there are also fibres that are just bent to a high degree for example in the punch feed area or in the ring groove. During the offsetting and upsetting phases, the TPC sheet is partially compacted and bent while the thickness of the metal sheet remains constant. At load levels between 20 and 35 $\mathrm{kN}$ the forming of the undercut occurs. It can be seen that the undercuts of the finished joints are not symmetrical to the punch axis although the tools are concentrically aligned (cf. Fig. 6-finished joint $1,90^{\circ}$ ). Furthermore the forming of the bottom area in the metal sheet is characterised by imprints of the TPC and a thinner cross-section in comparison to the boundary area of the bottom.

\subsection{Bottom area}

The material structure in the offsetting phase at a load level of $14.3 \mathrm{kN}$ is shown in Fig. 6-offsetting. The material structure is still intact and the layer structure as well as matrix-rich zones are still identifiable like in the initial material (cf. Fig. 2). Because of the compression between the punch and the spring-loaded anvil, first fibre fractures occur. All layers show fractures in the bottom area (Fig. 7). Especially, the fragments of three bottom layers (6-8) interact and overlap with each other (cf. Fig. 7e-g).

The subsequent upsetting leads to further changes of the material structure. During penetration of the punch, the bulge of the metal sheet is formed, which increasingly deflects the fibres. Thus, the resultant fibre tension leads to fibre fracture in each layer. Additionally, the fibres are compacted or moved in radial direction. Here, the relative movement of the layers might be the reason for layer debonding. This becomes visible as gaps (cf. Fig. 6-upsetting).

In the last phase (flow pressing) before the joint is finished, the undercut is formed and the compression increases. The high compression leads to fibre imprints in the bottom area of the metal sheet. Here, the sheet is compressed up to $10 \%$ of the initial thickness (cf. Table 2), which makes the identification of each layer impossible. In comparison to the off- and upsetting phases, the metal sheet is transformed from a convex to a concave shape on the TPC faced side. The minimum bottom thickness occurs in the centre. In comparison of the finished joint to the level set of 35.5 $\mathrm{kN}$ the minimum thickness of the TPC is further reduced (boundary area).

\subsection{Ring groove area}

At the beginning of the offsetting phase the ring groove is partially filled with fibres and matrix. Fibre fracture caused
Fig. 5 Joining force-displacement curve during clinching with the three multistage tests and the maximum joining force $F_{\text {max }}$ (red dots) with a microsection of final templing results

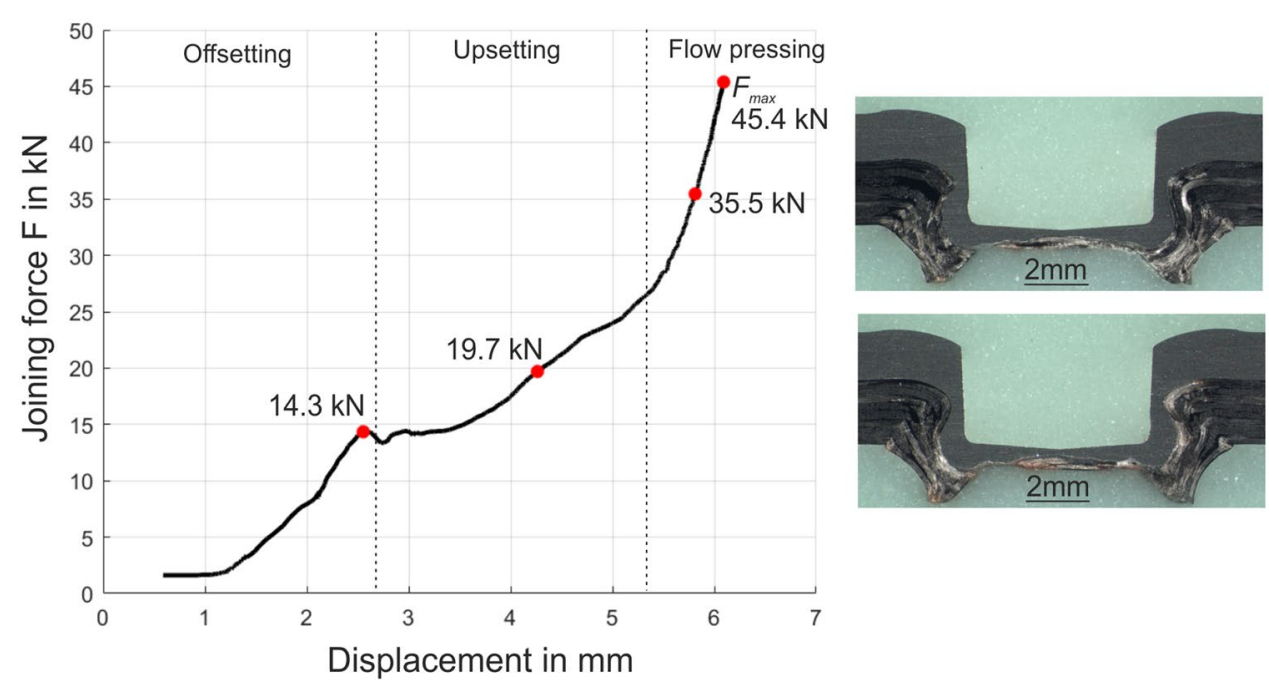


Fig. 6 Cross-sections along the $0^{\circ}$ and $90^{\circ}$ fibre direction of the reconstructed volume $0^{\circ}$
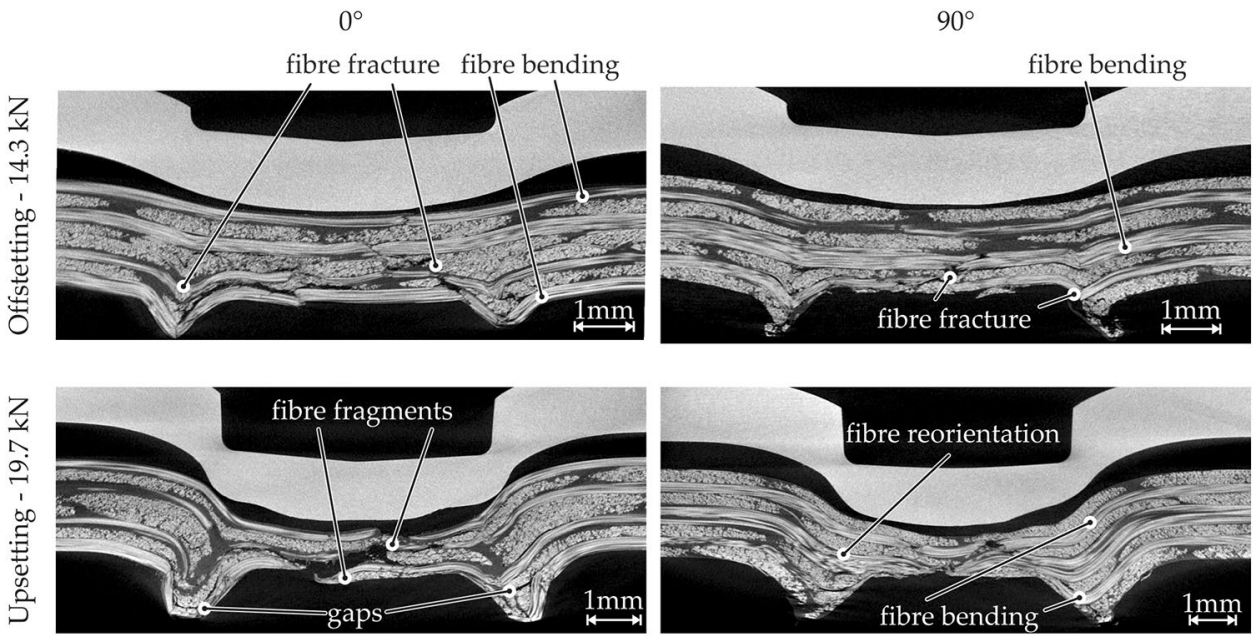

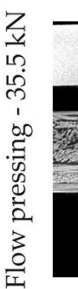
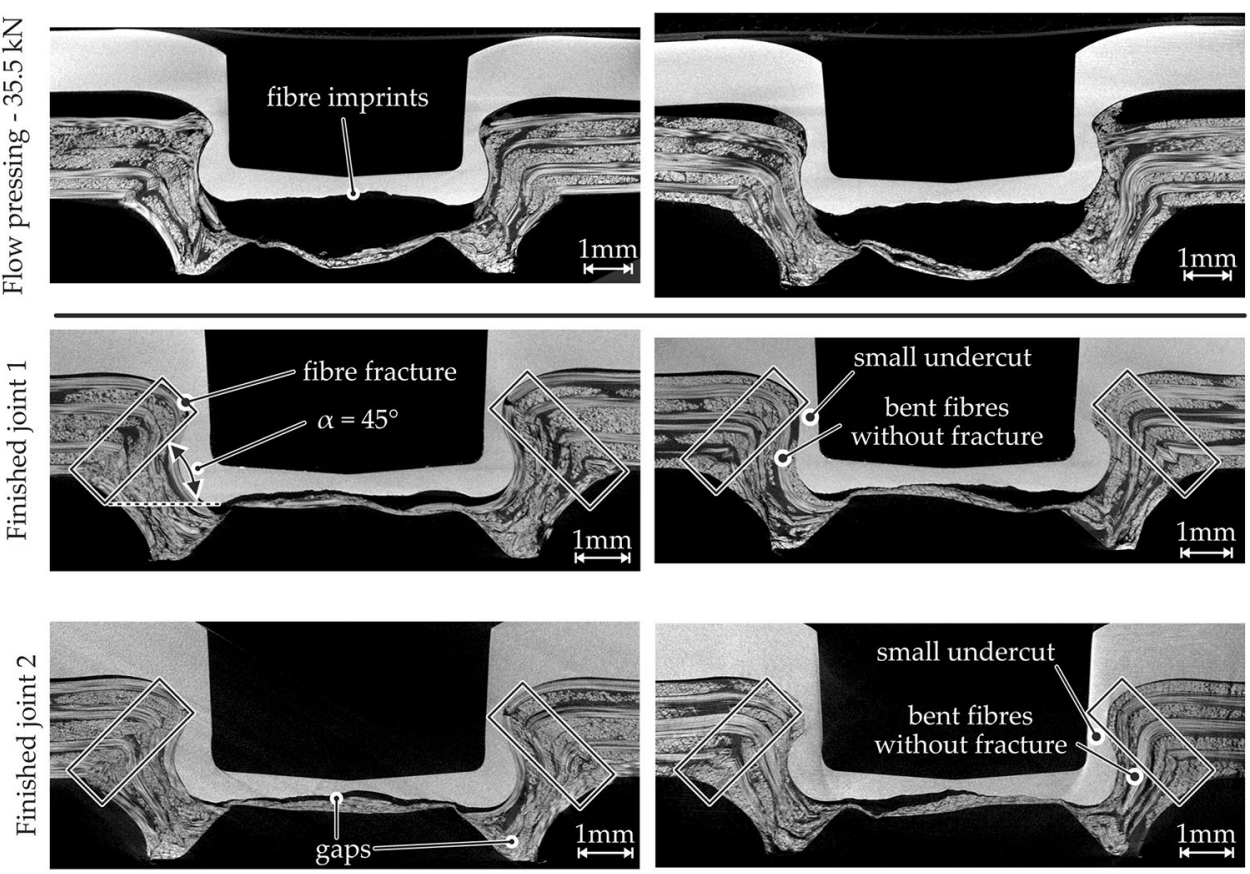

Table 2 Sheet thickness $t_{i}$ in $\mathrm{mm}$ of the bottom area at the different joining load levels $F$

\begin{tabular}{llllllllll}
\hline$F_{j}$ in $\mathrm{kN}$ & $t_{1}$ & $t_{2}$ & $t_{3}$ & $t_{4}$ & $t_{5}$ & $t_{6}$ & $\varnothing t$ & Initial & Ratio $R$ \\
\hline 14.3 & & & & & & & & & \\
Metal & 1.35 & & & & & & & 1.52 & 0.88 \\
TPC & 1.58 & 1.67 & 1.69 & & & & 1.65 & 2.00 & 0.82 \\
19.7 & & & & & & & & & \\
Metal & 1.34 & & & & & & 0.99 & 2.00 & 0.50 \\
TPC & 1.06 & 0.99 & 1.03 & 0.89 & & & & & \\
35.5 & & & & & & & & 1.52 & - \\
Metal & & & & & & & & & \\
TPC & 0.21 & 0.06 & 0.09 & 0.19 & 0.07 & 0.31 & 0.15 & 2.00 & 0.08 \\
\hline
\end{tabular}

by bending can be observed in the layers four until eight above the ring groove. Furthermore, gaps between the layers can be detected (cf. Fig. 6-offsetting). It is also evident that fibres were reorientated and matrix-rich zones occurred (cf. Fig. 8). 
Fig. 7 Cross-section of the layers in the bottom area with yarn fracture in each layer at offsetting phase

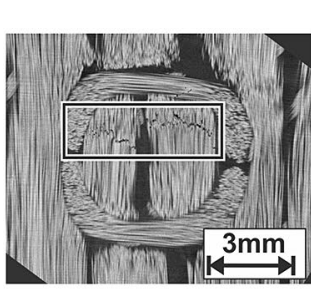

(a) Layer 1

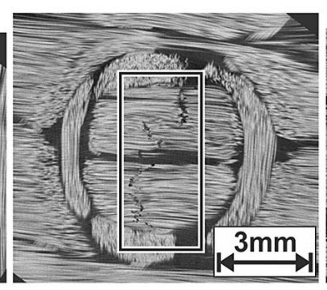

(b) Layer 2

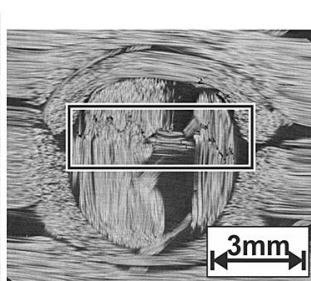

(c) Layer 3

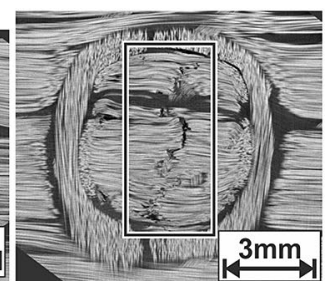

(d) Layers 4 and 5

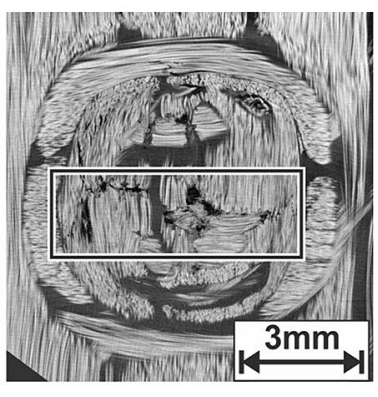

(e) Layer 6

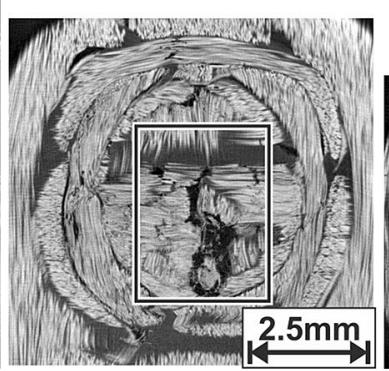

(f) Layer 7

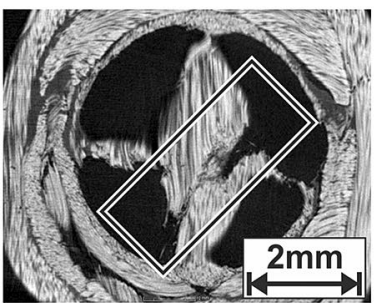

(g) Layer 8
During the upsetting phase the ring groove is completely filled. While pressing the fibres of three bottom layers are folded leading to fibre breakage (cf. Fig. 6upsetting). Figure 6 -upsetting $90^{\circ}$ also shows that the cross-section shape of the orthogonal yarns is distorted. In Fig. 9 the matrix-rich zones were also pressed in the ring groove. Additionally, the fibres of the bottom layer which are tangent to the ring groove are shifted in lateral direction (reorientation).

In contrast to the prior state, fibre fracture occurs to the reorientated fibres in the flow pressing phase (cf. Fig. 10). In the ring groove matrix-rich zones can be detected. In comparison to the bottom area, all layers can be identified in the ring groove area (cf. Fig. 6-flow pressing).

In comparison to the level set of $35.7 \mathrm{kN}$, no additional phenomena are observed in the finished joint (cf. Fig. 11). As can be seen, the resultant material structure of the finished clinch joints vary extremely (matrix rich zones and reorientated fibres with fracture). This can be explained by the heterogeneous material structure.

\subsection{Neck area}

The formation of the neck area starts after the upsetting phase (cf. Fig. 6-upsetting). The fibres are bent in alignment with the undercut of the metal sheet. Despite bending it is notable that no fracture can be observed in upper fibres that run underneath the undercut (cf. Fig. 6-90 finished joint 1 and finished joint 2). Additionally, the undercuts are small in proximity to these fibres in comparison to the respective opposite side.
Fig. 8 Bottom view of the joint with focus on fibre fragments in the ring groove at a level set of $14.3 \mathrm{kN}$
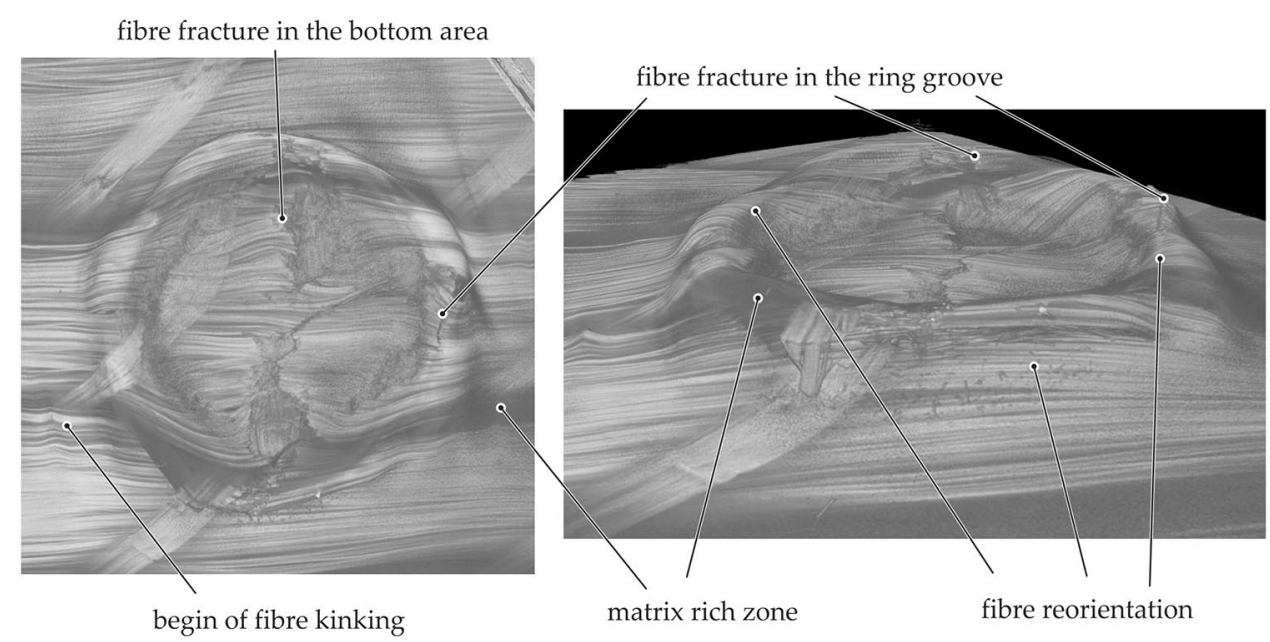

with focus on fibre reorientation
Fig. 9 Bottom view of the joint in the ring groove at a level set of $19.7 \mathrm{kN}$
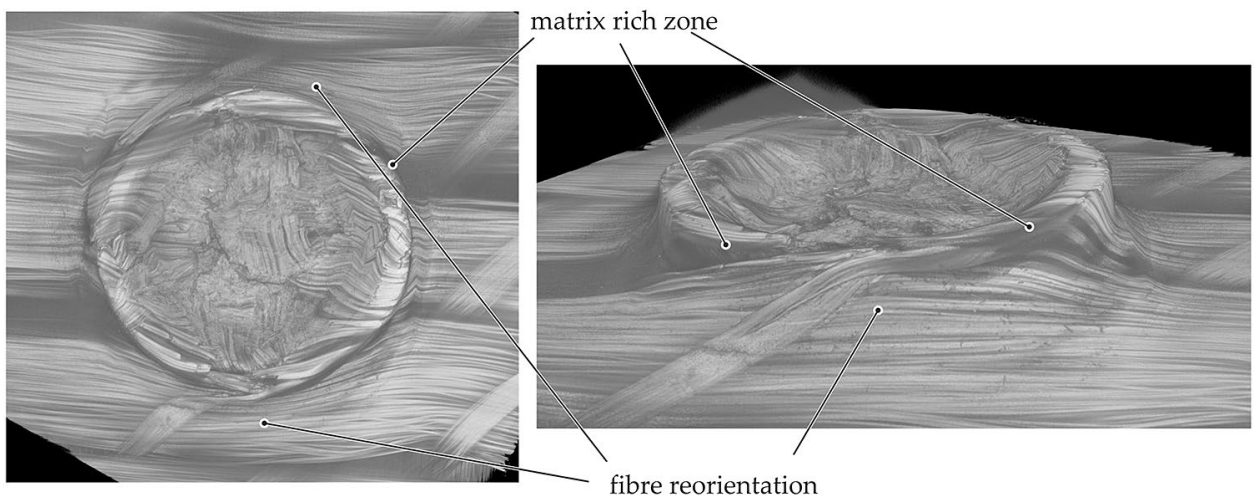

Fig. 10 Bottom view of the joint with focus on fibre fracture in the ring groove at a level set of $35.7 \mathrm{kN}$

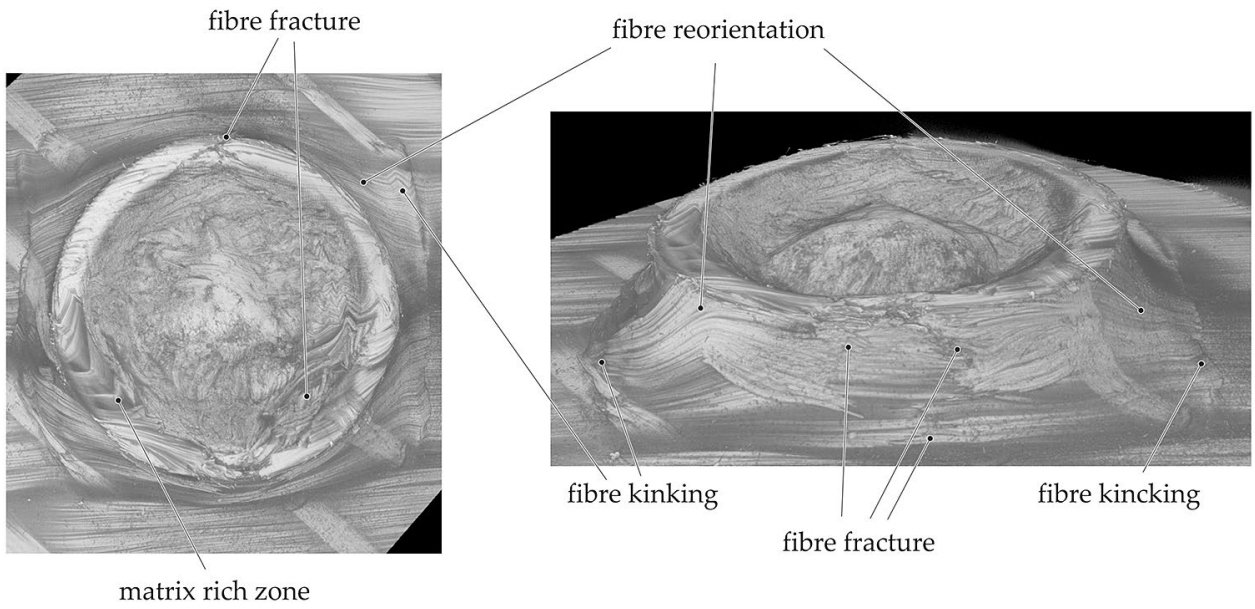

\subsection{Punch feed area}

The offsetting phase is characterised by bending in all layers. This bending leads to inter fibre failure in the upper layers. In the following upsetting phase, besides the fibre bending in punching direction, a shifting in radial direction occurs. This fibre reorientation can be seen in the layers four and five (cf. Fig. 6-upsetting). Especially notable are the fibre cracks (kinking) that occur in an angle of $45^{\circ}$ to the horizontal plane in the main directions (cf. Fig. 6-flow pressing). This phenomenon can be seen after the upsetting phase in a weak form (cf. Fig. 9) and it becomes more pronounced in the subsequent states.

\subsection{Outer area}

At the level set of $35.5 \mathrm{kN}$ an excessive fibre rearrangement of yarns is observed (cf. Fig. 12). All yarns in the layer are meandered around the joint. However, such a strong reorientation in the outer area could not be observed at other specimens.

\section{Discussion}

In conclusion, the multi-layered material allows a clear identification of layers in all areas during the process states except the bottom area. This enables an identification of the resultant material structure caused by the joining process. Therefore, matrix rich zones, fibre reorientation, failure phenomena and the formation of the undercut can set in relation to the interaction between the composite and the tools.

The undercuts are small in proximity to intact fibres that run in radial direction. Consequently, it can be concluded that theses fibres restrain the formation of the undercut which leads to an unsymmetrical joint.

The process and the material behavior are driven by the temperature-dependent elastic and plastic behaviour of TPC. As a result, after the release of the finished joint, the elastic deformations reset. Compared to an ondulated fabric TPC, the elastic elongation of multi layered TPC is reduced caused by the straight fibre path. Hence, the yield strength of the fibres is reaches at a lower punch displacement. This in turn leads higher residual stresses and less elastic potential for the deflection of fibres which might be the reason for debonding. 
Fig. 11 Bottom view of two finished joints with focus on fibre fracture and matrix-rich zones in the ring groove

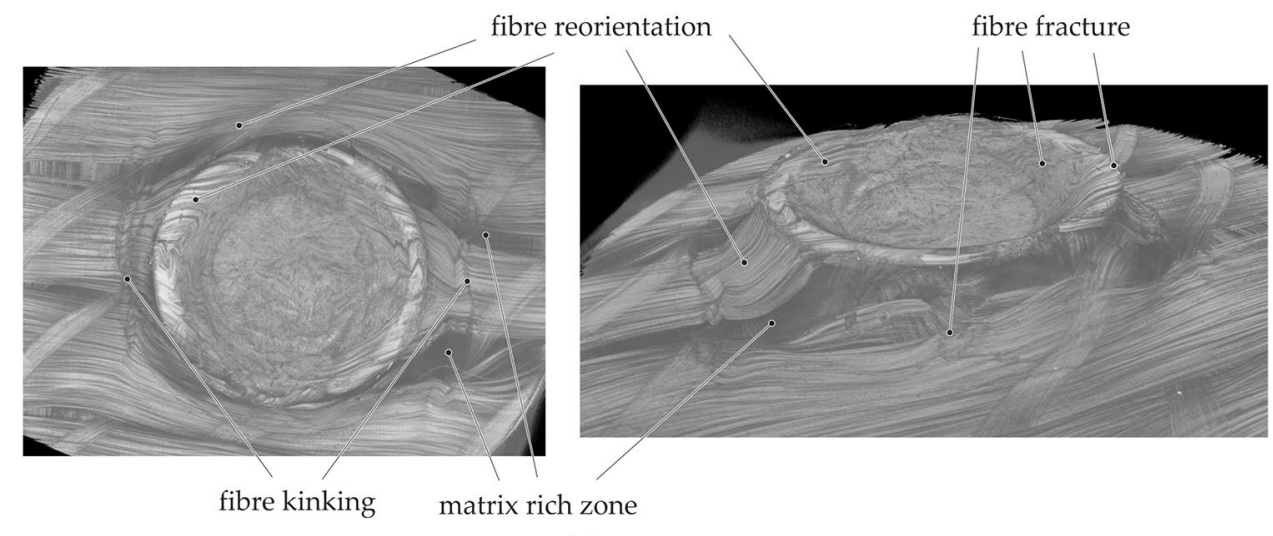

(a)

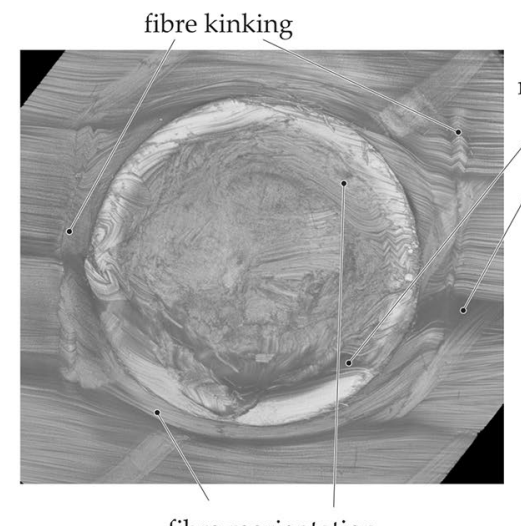

fibre reorientation

(b)

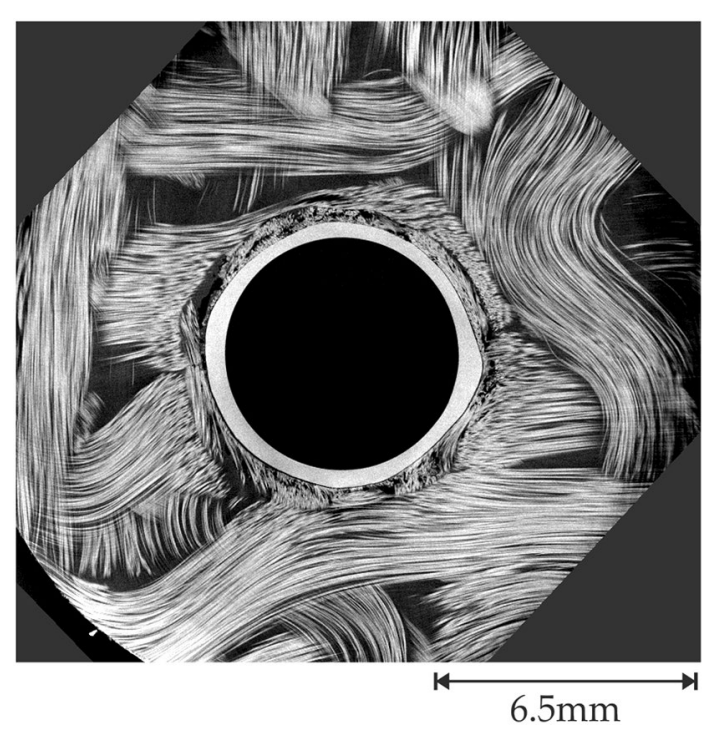

Fig. 12 Fibre reorientation in the third layer in the outer area in cause of matrix migration processes from the bottom and neck area during flow pressing

Using micrographs for material structure analysis is limited to one cross-section. In contrast, the $\mathrm{CT}$ analysis offers the possibility to investigate the joining zone in all spacial dimensions simultaneously and reduces the preparation effort. With respect to the heterogeneous initial material structure it is possible to explain all phenomena using only one joint specimen. A specific phenomenon can be investigated in several cross-sections of the same specimen. This enables a continuous description of this phenomenon, which is difficult to achieve with micrographs especially in consideration of the heterogeneity of composites.

The effects leading to debonding could not be specified in detail. Furthermore, the phenomena between the multi stage tests remain unknown. In future, in-situ CT investigations could expand this knowledge and enable a provision of a better understanding of the interactions between the yarns.

\section{Summary}

The paper presents a CT analysis of hotclinched joints made of aluminium and a multi-layered GF-PA6 sheet. In detail, the resultant material structure of three different multistage tests with varying joining forces and finished joints is analysed. It could be shown, that the material structure is characterized by fibre fracture, fibre shifting in radial direction 
in the bottom and ring groove area. In contrast, in the punch feed and neck area fibre bending occurs. Notable is especially the fibre kinking in all layers at an angel of $45^{\circ}$ to sheet plane in the punch feed area. The analysis also shows that fibre fracture and debonding leads to gaps. Matrix flow processes, as they occur in joining processes that operate above melting temperature of the matrix, cannot be detected (cf. [18]).

The analysis of the material structure enables a further development of clinching process in terms of tool design and process parameters. The Hotclinching process can be transferred to other matrix systems and reinforcement architectures, offering high potential for use in many applications.

Acknowledgements The authors acknowledge the interdisciplinary cooperation between the sub-projects A01, A03 and $\mathrm{C} 04$ within the DFG TRR 285 project; A01 for the provision of the joint specimens, A03 for a detailed analysis of the phenomena and C04 for the CT-analysis.

Funding Open Access funding enabled and organized by Projekt DEAL. This research was funded by the Deutsche Forschungsgemeinschaft (DFG, German Research Foundation)_-TRR 285-Project-ID 418701707, in cooperation of the sub-projects A01, A03 and C04.

Open Access This article is licensed under a Creative Commons Attribution 4.0 International License, which permits use, sharing, adaptation, distribution and reproduction in any medium or format, as long as you give appropriate credit to the original author(s) and the source, provide a link to the Creative Commons licence, and indicate if changes were made. The images or other third party material in this article are included in the article's Creative Commons licence, unless indicated otherwise in a credit line to the material. If material is not included in the article's Creative Commons licence and your intended use is not permitted by statutory regulation or exceeds the permitted use, you will need to obtain permission directly from the copyright holder. To view a copy of this licence, visit http://creativecommons.org/licenses/by/4.0/.

\section{References}

1. Gude M, Meschut G, Zäh MF, Lieberwirth H, Tekkaya E (2018) Forel studie-ressourceneffizienter leichtbau für die mobilität: Wandel-prognose-transfer. Technical report, Institut für Leichtbau und Kunststofftechnik

2. Mucha J (2017) Clinching technology in the automotive industry. Arch Automot Eng Arch Motoryz 72(2):75-94

3. Galińska A, Galiński C (2020) Mechanical joining of fibre reinforced polymer composites to metals-a review. Part II: riveting, clinching, non-adhesive form-locked joints, pin and loop joining. Polymers 12(8):1681. https://doi.org/10.3390/polym12081681

4. Lambiase F, Scipioni SI, Lee C-J, Ko D-C, Liu F (2021) A stateof-the-art review on advanced joining processes for metal-composite and metal-polymer hybrid structures. Materials 14(8):1890. https://doi.org/10.3390/ma14081890

5. Gröger B, Troschitz J, Vorderbrüggen J, Vogel C, Kupfer R, Meschut G, Gude M (2021) Clinching of thermoplastic composites and metals - a comparison of three novel joining technologies. Materials 14(9):2286. https://doi.org/10.3390/ma14092286
6. Lee C-J, Lee S-H, Lee J-M, Kim B-H, Kim B-M, Ko D-C (2014) Design of hole-clinching process for joining CFRP and aluminum alloy sheet. Int J Precis Eng Manuf 15(6):1151-1157. https://doi. org/10.1007/s12541-014-0450-6

7. Lee C-J, Kim B-M, Kang B-S, Song W-J, Ko D-C (2017) Improvement of joinability in a hole clinching process with aluminum alloy and carbon fiber reinforced plastic using a spring die. Compos Struct 173:58-69. https://doi.org/10.1016/j.compstruct. 2017.04.010

8. Lambiase F, Paoletti A (2018) Friction-assisted clinching of aluminum and CFRP sheets. J Manuf Process 31:812-822. https:// doi.org/10.1016/j.jmapro.2018.01.014

9. Lambiase F, Durante M, Ilio AD (2016) Fast joining of aluminum sheets with glass fiber reinforced polymer (GFRP) by mechanical clinching. J Mater Process Technol 236:241-251. https://doi.org/ 10.1016/j.jmatprotec.2016.04.030

10. Lambiase F, Ko D-C (2016) Feasibility of mechanical clinching for joining aluminum AA6082-T6 and Carbon Fiber Reinforced Polymer sheets. Mater Des 107:341-352

11. Lambiase F, Ko D-C (2017) Two-steps clinching of aluminum and carbon fiber reinforced polymer sheets. Compos Struct 164:180188. https://doi.org/10.1016/j.compstruct.2016.12.072

12. Lin P-C, Lin J-W, Li G-X (2018) Clinching process for aluminum alloy and carbon fiber-reinforced thermoplastic sheets. Int $\mathrm{J}$ Adv Manuf Technol 97(1-4):529-541. https://doi.org/10.1007/ s00170-018-1960-7

13. Seidlitz H, Ulke-Winter L, Kroll L (2014) New joining technology for optimized metal/composite assemblies. J Eng 2014:1-11. https://doi.org/10.1155/2014/958501

14. Gude M, Vogel C, Gröger B (2019) Simulation-aided development of a robust thermoclinching joining process for hybrid structures with textile reinforced thermoplastic composites and metallic components. Mater Werkst 50(8):1027-1038. https://doi.org/10. 1002/mawe. 201900036

15. Vorderbrüggen J, Gröger B, Kupfer R, Hoog A, Gude M, Meschut $G$ (2019). Phenomena of forming and failure in joining hybrid structures: experimental and numerical studies of clinching thermoplastic composites and metal. https://doi.org/10.1063/1.51125 80

16. Coppieters S, Zhang H, Xu F, Vandermeiren N, Breda A, Debruyne D (2017) Process-induced bottom defects in clinch forming: simulation and effect on the structural integrity of single shear lap specimens. Mater Des 130:336-348. https://doi.org/10. 1016/j.matdes.2017.05.077

17. Troschitz J, Vorderbrüggen J, Kupfer R, Gude M, Meschut G (2020) Joining of thermoplastic composites with metals using resistance element welding. Appl Sci 10(20):7251. https://doi. org/10.3390/app10207251

18. Troschitz J, Kupfer R, Gude M (2019) Process-integrated embedding of metal inserts in continuous fibre reinforced thermoplastics. In: 2nd CIRP Conference on Composite Material Parts Manufacturing, 10-11 October 2019, Advanced Manufacturing Research Centre, UK. Procedia CIRP 85:84-89. https://doi.org/10.1016/j. procir.2019.09.039

19. Drossel WG, Jäckel M (2014) New die concept for self-pierce riveting materials with limited ductility. Key Eng Mater 611612:1452-1459. https://doi.org/10.4028/www.scientific.net/KEM. $611-612.1452$

Publisher's Note Springer Nature remains neutral with regard to jurisdictional claims in published maps and institutional affiliations. 